\title{
A numerical simulation of supraglacial heat advection and its influence on ice melt
}

\author{
R. D. MOORE \\ Department of Geography, Simon Fraser University, Burnaby, British Columbia V5A 1S6, Canada
}

\begin{abstract}
Energy exchange between the atmosphere and a melting glacier surface is mediated by the presence of a water layer. Under conditions of rapid melt and/or heavy rainfall, the possibility exists that a supraglacial run-off layer can advect sensible heat and influence the spatial variations of melt. The potential magnitude of such advection was investigated by numerically solving differential equations expressing the mass and energy balances of a two-dimensional run-off layer. Solutions were obtained for conditions typical of rainfall events, in which the potential for supraglacial heat advection should be maximal. The solutions indicate that advection cannot influence macro-scale melt patterns and surface morphology, except perhaps under heavy rainfall and/or rapid melt conditions, but can possibly cause micro-scale variations in ice melt. One-dimensional energy-balance models, which have normally been applied over glacier surfaces, should remain valid for most conditions.
\end{abstract}

\section{INTRODUCTION}

Most glacier-surface energy-balance research has assumed energy exchanges to be one-dimensional (Martin, 1975; Hay and Fitzharris, 1988; Munro, 1989). How-

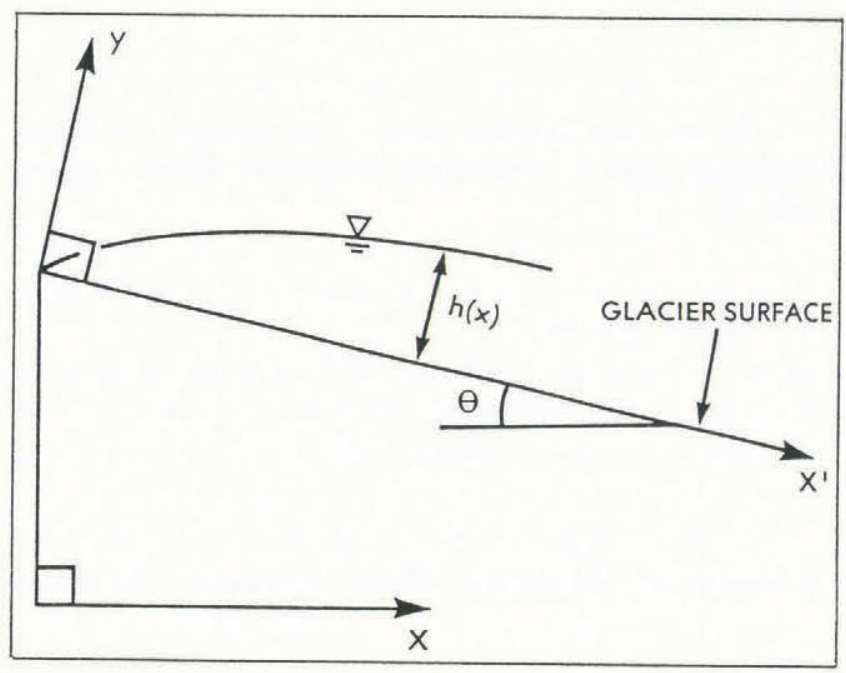

Fig. 1. Geometry of assumed boundary conditions. The coordinate $x$ is the horizontal distance from the top of the slope, $x^{\prime}$ represents the ice surface and $y$ represents the coordinate perpendicular to the ice surface. $h(x)$ represents the depth of water (perpendicular to the ice surface) at a horizontal distance $x$ from the top of the slope. ever, Kazanskiy (1982) argued that flowing supraglacial run-off layers can advect significant quantities of energy, thereby modifying spatial melt patterns and influencing surface morphology. In addition, heat advection into moulins and crevasses may have significance for intraand subglacial hydraulic conditions, as numerical studies have shown flow processes within and below glaciers to be sensitive to water temperature (Clarke, 1982; Spring and Hutter, 1981).

Supraglacial advection is likely to be greatest under conditions in which major energy inputs are in forms other than solar radiation, most of which would penetrate through a run-off layer to the underlying ice. Such conditions are commonly found during warm rainstorms on glaciers in maritime climates, such as those in New Zealand and coastal British Columbia (Marcus and others, 1985). In this paper, an attempt is made to estimate the magnitude of heat advection by supraglacial run-off and its impact on glacier melt patterns during rainfall situations. As a consequence of the difficulties involved in measuring temperature and velocity profiles in runoff layers, recourse is made to numerical simulation of supraglacial mass and energy exchanges associated with surface run-off.

\section{THEORETICAL BACKGROUND}

The situation assumed here is a planar ice surface bounded at the upper end by a crevasse, and with a coordinate system as shown in Figure 1. Steady-state conditions are assumed for computational convenience. 
The formulation is based on the conservation laws for energy and mass, which for a run-off layer can be respectively expressed as

$$
\frac{\mathrm{d} J}{\mathrm{~d} x}=Q_{*}+Q_{\mathrm{H}}+Q_{\mathrm{E}}+Q_{\mathrm{P}}-Q_{\mathrm{W}}
$$

and

$$
\frac{\mathrm{d} q}{\mathrm{~d} x}=R+\frac{Q_{\mathrm{W}}}{\rho L_{\mathrm{f}}}+\frac{Q_{\mathrm{E}}}{\rho L_{\mathrm{v}}}+\frac{g q \sin \theta}{L_{\mathrm{f}}}
$$

where $x$ is horizontal distance from the top of the slope $(\mathrm{m}) ; J$ is advective heat flux $\left(\mathrm{W} \mathrm{m}^{-1}\right) ; Q_{*}$ is net radiative exchange $\left(\mathrm{W} \mathrm{m}^{-2}\right) ; Q_{\mathrm{H}}$ is sensible-heat transfer from the atmosphere $\left(\mathrm{W} \mathrm{m}{ }^{-2}\right) ; Q_{\mathrm{E}}$ is latent-heat transfer from the atmosphere $\left(\mathrm{W} \mathrm{m}^{-2}\right) ; Q_{\mathrm{P}}$ is sensible-heat transfer from precipitation $\left(\mathrm{W} \mathrm{m}^{-2}\right) ; \rho$ is density of water $\left(\mathrm{kg} \mathrm{m}^{-3}\right) ; g$ is gravitational acceleration $\left(\mathrm{m} \mathrm{s}^{-2}\right) ; q$ is specific discharge of run-off layer $\left(\mathrm{m}^{2} \mathrm{~s}^{-1}\right) ; \theta$ is slope of ice surface (deg); $Q_{\mathrm{W}}$ is energy flux through the run-off layer to the underlying ice $\left(\mathrm{W} \mathrm{m}^{-2}\right) ; R$ is rainfall rate $\left(\mathrm{m} \mathrm{s}^{-1}\right) ; L_{\mathrm{f}}$ is latent heat of fusion $\left(\mathrm{J} \mathrm{kg}^{-1}\right)$; and $L_{\mathrm{v}}$ is latent heat of vaporization $\left(\mathrm{J} \mathrm{kg}^{-1}\right)$. The fluxes $Q_{*}, Q_{\mathrm{H}}, Q_{\mathrm{E}}, Q_{\mathrm{P}}$ and $Q_{\mathrm{W}}$ are rate of energy transfer per unit width of glacier per unit horizontal distance. It is assumed that the frictional heat generation (the last term in Equation (2)) goes directly to melting ice, and does not affect the energy balance of the water layer.

The advective flux, $J$, is defined at any point $x$ by

$$
J=\rho c_{\mathrm{w}} \int_{0}^{h} u(y) T(y) \mathrm{d} y
$$

where $c_{\mathrm{w}}$ is heat capacity of water $\left(\mathrm{J} \mathrm{m}^{-3}{ }^{\circ} \mathrm{C}^{-1}\right) ; u(y)$ is water velocity $\left(\mathrm{m} \mathrm{s}^{-1}\right) ; T(y)$ is water temperature $\left({ }^{\circ} \mathrm{C}\right)$; and $h$ is water depth (m). The flux due to sensible heat of precipitation is given by

$$
Q_{\mathrm{P}}=\rho c_{\mathrm{w}} R T_{\mathrm{r}}
$$

where $T_{\mathrm{r}}$ is raindrop temperature $\left({ }^{\circ} \mathrm{C}\right)$. The turbulent exchanges of sensible and latent heat are often expressed by equations of the form

$$
Q_{\mathrm{H}}=\beta u_{\mathrm{a}}\left(T_{\mathrm{a}}-T_{0}\right)
$$

and

$$
Q_{\mathrm{E}}=\beta u_{\mathrm{a}}\left(e_{\mathrm{a}}-e_{0}\right) / \gamma
$$

where $u_{\mathrm{a}}$ is wind speed $1 \mathrm{~m}$ above the surface $\left(\mathrm{m} \mathrm{s}^{-1}\right)$; $T_{\mathrm{a}}$ is air temperature $1 \mathrm{~m}$ above the surface $\left({ }^{\circ} \mathrm{C}\right) ; T_{0}$ is temperature at the surface $\left({ }^{\circ} \mathrm{C}\right) ; \beta$ is a transfer coefficient $\left(\mathrm{J} \mathrm{m}^{-3}{ }^{\circ} \mathrm{C}^{-1}\right) ; \gamma$ is the psychrometric constant $\left(\mathrm{mbar}^{\circ} \mathrm{C}^{-1}\right) ; e_{\mathrm{a}}$ is vapour pressure of air $1 \mathrm{~m}$ above the surface (mbar); and $e_{0}$ is vapour pressure at the surface (mbar).

To evaulate $Q_{*}, Q_{\mathrm{H}}, Q_{\mathrm{E}}$ and $Q_{\mathrm{P}}$, the assumptions invoked by Anderson (1973) to compute snowmelt during rain events have been used. These are (1) the air is saturated; (2) $T_{\mathrm{r}}=T_{\mathrm{a}}$; (3) solar radiation is negligible; (4) the atmosphere emits as a black body with temperature $T_{\mathrm{a}}$. Under these assumptions, $Q_{*}$ can be approximated by

$$
Q_{*}=4 \sigma\left(T_{\mathrm{s}}+273.2\right)^{3}\left(T_{\mathrm{a}}-T_{\mathrm{s}}\right)
$$

where $\sigma$ is the Stefan-Boltzmann constant $\left(\mathrm{W} \mathrm{m}^{-2} \mathrm{~K}^{-4}\right)$. As the surface and the air are saturated, $e_{0}$ and $e_{\mathrm{a}}$ are the respective vapour pressures at temperatures $T_{0}$ and $T_{\mathrm{a}}$. Nakawo and Young (1982) suggested that $\beta=4.89$ is a reasonable value for glacier surfaces; this value is used in Equations (5) and (6) to calculate $Q_{\mathrm{H}}$ and $Q_{\mathrm{E}}$ given $T_{\mathrm{a}}$ and $T_{0}$.

Computation of $Q_{\mathrm{W}}$ depends on whether flow is laminar or turbulent. For laminar flow, the problem is similar to the condensation-film flow case investigated by Nusselt (1916; cited in McAdams (1954)). Nusselt solved the problem by arguing that heat exchange into the surface underlying the water is purely by conduction, and the temperature distribution should be linear. The rate of energy transfer is then

$$
Q_{\mathrm{W}}=k\left(T_{0}-T_{\mathrm{m}}\right) / h
$$

where $T_{\mathrm{m}}$ is the melting temperature $\left({ }^{\circ} \mathrm{C}\right)$ and $k$ is thermal conductivity of water $\left(\mathrm{W} \mathrm{m}^{-1}{ }^{\circ} \mathrm{C}^{-1}\right)$. The depth of flow, $h$, is given by

$$
h=[(3 \mu q) /(\gamma g \sin \theta)]^{1 / 3}
$$

(Henderson, 1966). $T_{0}$ can be derived from $J$ and $q$ by integrating Equation (3), given the following profiles for water temperature and velocity in laminar flow:

$$
\begin{aligned}
& T(y)=\left(T_{0}-T_{\mathrm{m}}\right) y / h+T_{\mathrm{m}} \\
& u(y)=(\rho g \sin \theta / \mu)\left(h y-y^{2} / 2\right)
\end{aligned}
$$

where $\mu$ is the dynamic viscosity of water $\left(\mathrm{kg} \mathrm{m}^{-1} \mathrm{~s}^{-1}\right)$. If a bulk water temperature is defined by

$$
T_{\mathrm{b}}=J /\left(\rho c_{\mathrm{w}} q\right),
$$

then it can be shown that

$$
T_{0}=(8 / 5) T_{\mathrm{b}}-(3 / 5) T_{\mathrm{m}} .
$$

Flow becomes turbulent when the Reynolds number exceeds 2000, where the Reynolds number is defined by

$$
\operatorname{Re}=4 \rho q / \mu
$$

(Kreith, 1973). For turbulent flow, $T_{0}$ and $T_{\mathrm{b}}$ are assumed equal. A diagram of dimensionless temperature profiles given by Kreith (1973, p. 421) indicates this is reasonable for water. The heat transfer to the ice surface is calculated from

$$
Q_{\mathrm{W}}=\alpha\left(T_{\mathrm{b}}-T_{\mathrm{m}}\right) .
$$

Colburn (1933) showed that the coefficient $\alpha$ is given by

$$
\alpha=0.056 \operatorname{Re}^{1 / 5} \operatorname{Pr}^{1 / 3} k\left(\rho^{2} g / \mu^{2}\right)^{1 / 3}
$$

where $\operatorname{Pr}$ is the Prandtl number, equal to $c_{\mathrm{W}} \mu / k$.

Equations (1) and (2) were numerically integrated using a fourth-order Runge-Kutta routine with error control, using the relationships above to calculate the energy 
exchanges. Integrations were carried out for a number of combinations of $T_{\mathrm{a}}, u_{\mathrm{a}}, \theta$ and $R$. The combinations were selected to represent a range of atmospheric conditions, from those that appeared reasonable in comparison with the author's and others' experiences $\left(T_{\mathrm{a}}=4^{\circ} \mathrm{C}\right.$, $\left.u_{\mathrm{a}}=4 \mathrm{~m} \mathrm{~s}^{-1}, R=4 \mathrm{~mm} \mathrm{~h}^{-1}\right)$, to those that should be extreme $\left(T_{\mathrm{a}}=10^{\circ} \mathrm{C}, u_{\mathrm{a}}=10 \mathrm{~m} \mathrm{~s}^{-1}, R=40 \mathrm{~mm} \mathrm{~h}^{-1}\right)$. Two values of slope were used: $5^{\circ}$ and $20^{\circ}$.

\section{RESULTS}

Solutions for six sets of conditions are shown in Figures 2-7. All situations display similar patterns. Initially, flow is laminar, and the depth of water increases as flow increases downslope according to Equation (9). To maintain heat transfer through the water layer, the bulk and surface temperature must also increase, producing a decrease in the energy input at the water surface $\left(Q_{\mathrm{S}}=Q_{*}+Q_{\mathrm{H}}+Q_{\mathrm{E}}+Q_{\mathrm{P}}\right)$, according to Equations (4)(7). As a consequence of the conservation of energy, the use of energy to increase $T_{\mathrm{b}}$ as $q$ increases causes $Q_{\mathrm{W}}$ to be less than $Q_{\mathrm{S}}$.

When $\operatorname{Re}=2000$, the flow becomes turbulent and heat transfer occurs more efficiently. In fact, the heat transfer to the ice surface peaks at a level several times that of $Q_{\mathrm{S}}$, but drops to a level similar to that of the water-surface input after a short interval $(<10 \mathrm{~m})$. For example, for the conditions shown in Figure 2, the peak $Q_{\mathrm{W}}$ at the point of transition is over $1000 \mathrm{~W} \mathrm{~m}^{-2}$. These peaks have been edited out of the graphs in order to show
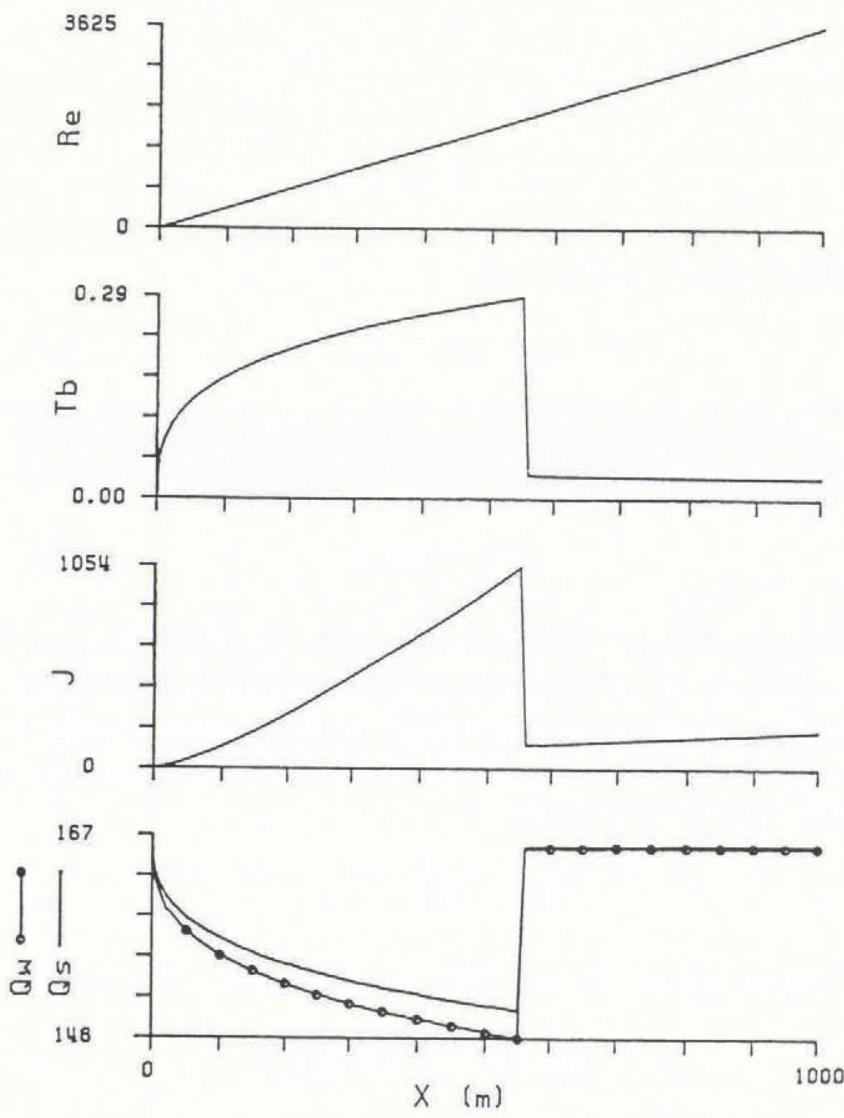

Fig. 2. Simulated values of $R e, T_{b}\left({ }^{\circ} C\right), J$ $\left(W m^{-1}\right), Q_{W}$ and $Q_{S}$ as functions of distance downslope for $T_{a}=4^{\circ} \mathrm{C}, u_{a}=4 \mathrm{~ms}^{-1}, \theta=5^{\circ}$ and $R=4 \mathrm{~mm} \mathrm{~h}^{-1}$.
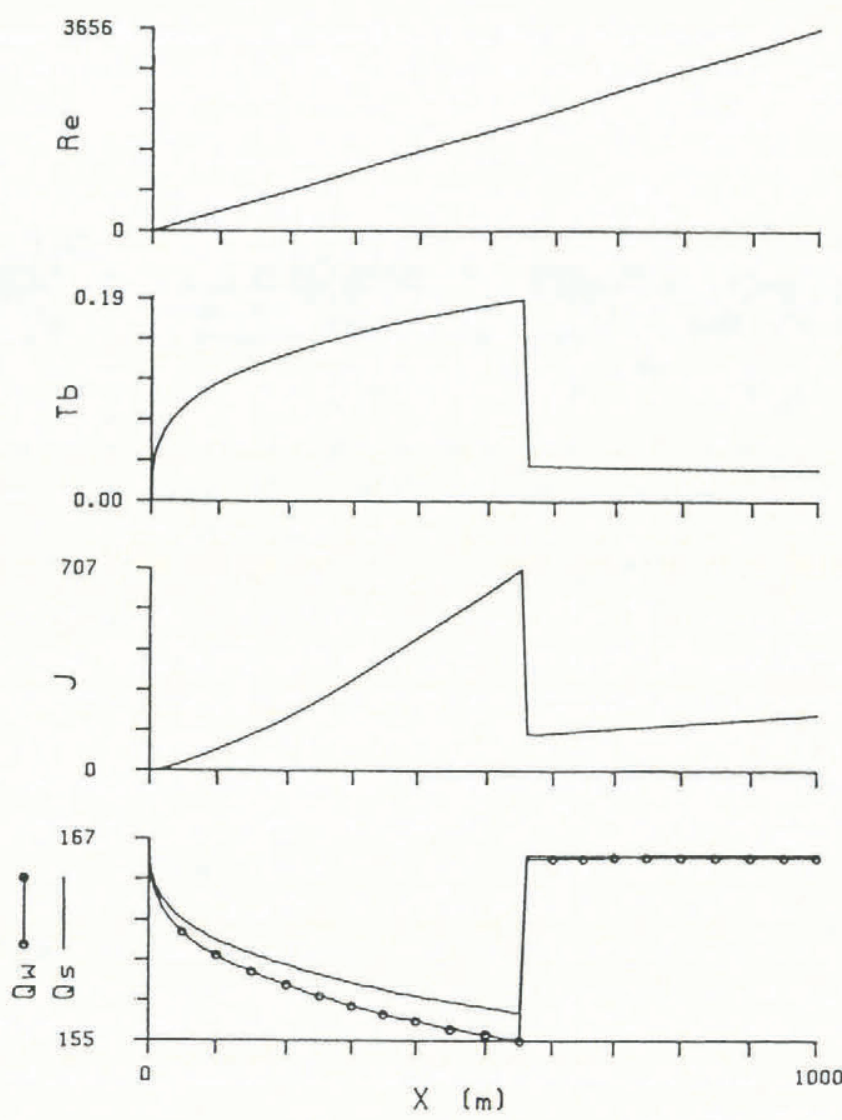

Fig. 3. As for Figure 2, but with $T_{a}=4^{\circ} \mathrm{C}$, $u_{a}=4 \mathrm{~mm} \mathrm{~s}^{-1}, \theta=20^{\circ}$ and $R=4 \mathrm{~mm} \mathrm{~h}^{-1}$.

more detail of the variations of $Q_{\mathrm{W}}$ and $Q_{\mathrm{S}}$ away from the transition point. In the turbulent region, $Q_{\mathrm{W}}$ and $Q_{\mathrm{S}}$ are both approximately equal to the value of $Q_{\mathrm{S}}$ at $x=0$ and constant downslope.

As can be seen, the main influence of advection on $Q_{\mathrm{W}}$ occurs in the laminar-flow zone. For the moderate melt and rainfall conditions shown in Figures 2 and 3, the maximum effect is approximately $5 \%$ of the value of $Q_{\mathrm{S}}$ for water-free conditions. The influence is greater for shallower slopes, as shown in Figures 2 and 3, because the water depth $h$ decreases with increasing slope for a given value of $q$. For the more extreme melt and/or rainfall conditions shown in Figures 4-7, the effect is greater, approaching $30 \%$ of the water-free value of $Q_{\mathrm{S}}$.

\section{DISCUSSION}

Although the simulation has provided quantitative results, only their qualitative aspects should be considered, especially in regard to how reality diverges from the assumptions. For example, the heat transfers were calculated from empirical formulae and using assumptions, such as $T_{\mathrm{r}}=T_{\mathrm{a}}$, which are certainly not generally true. In fact, the fundamental assumption of steadystate conditions is not true because the computed variations in $Q_{W}$ imply that the boundary conditions would change through time. However, from Figure 7, which is the most extreme case, the spatial range in melt rates is approximately $4.3 \mathrm{~mm} \mathrm{~h}^{-1}$, while the range for more moderate conditions is approximately $0.1 \mathrm{~mm} \mathrm{~h}^{-1}$ (see Fig. 3). Hence, significant changes in the ice-surface 

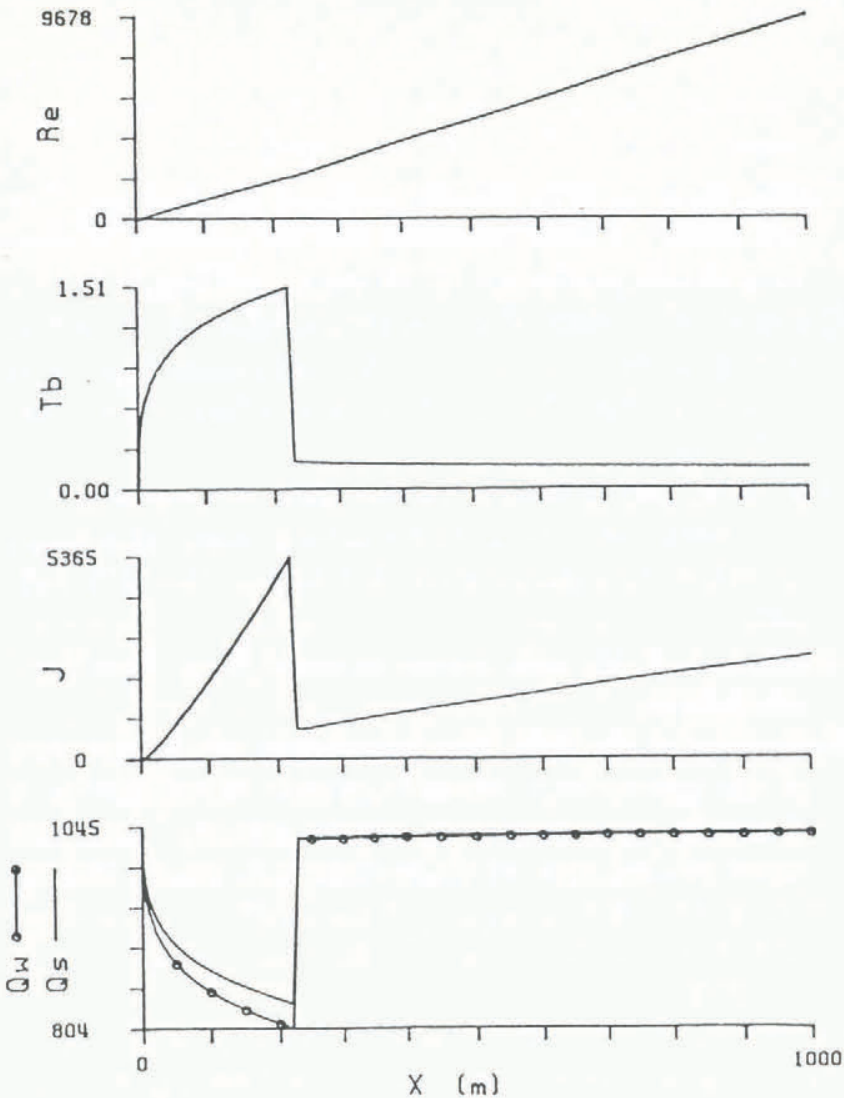

Fig. 4. As for Figure 2, but with $T_{a}=10^{\circ} \mathrm{C}$, $u_{a}=10 \mathrm{~ms}^{-1}, \theta=5^{\circ}$ and $R=4 \mathrm{~mm} \mathrm{~h}^{-1}$.
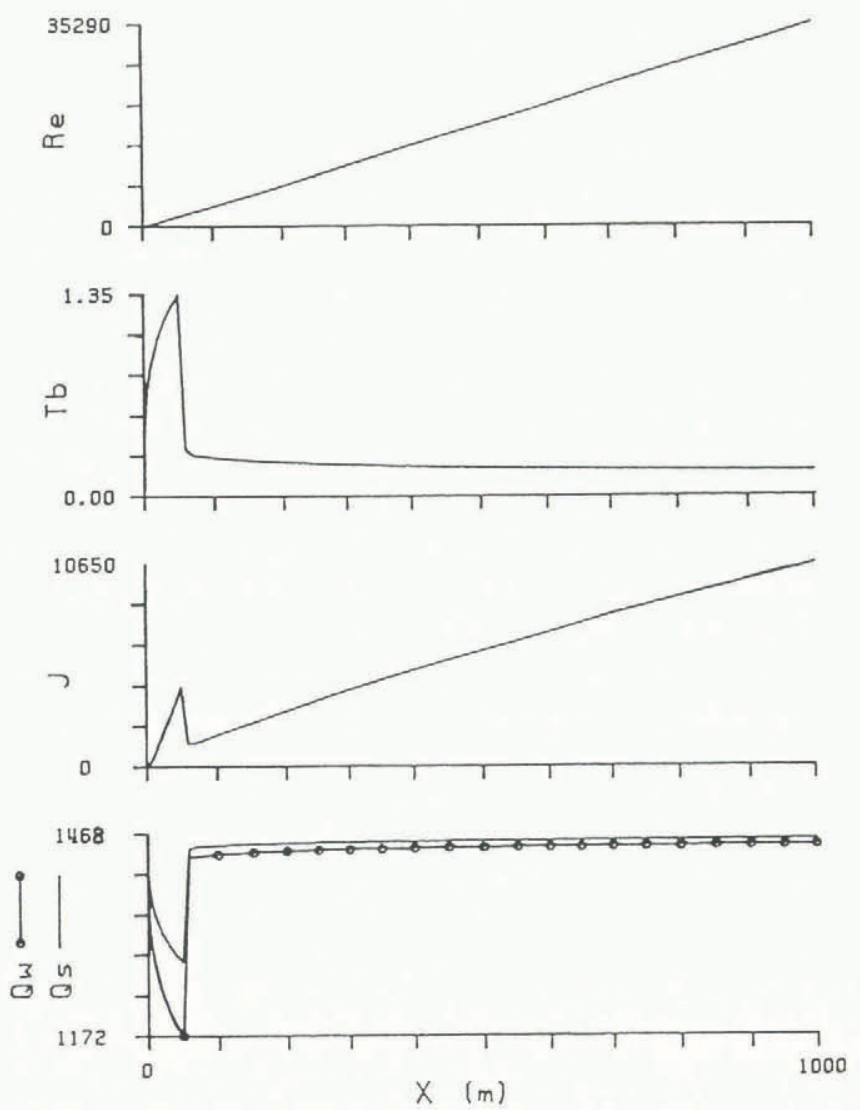

Fig. 5. As for Figure 2, but with $T_{a}=10^{\circ} \mathrm{C}$, $u_{a}=10 \mathrm{~m} \mathrm{~s}^{-1}, \theta=20^{\circ}$ and $R=40 \mathrm{~mm} \mathrm{~h}^{-1}$.
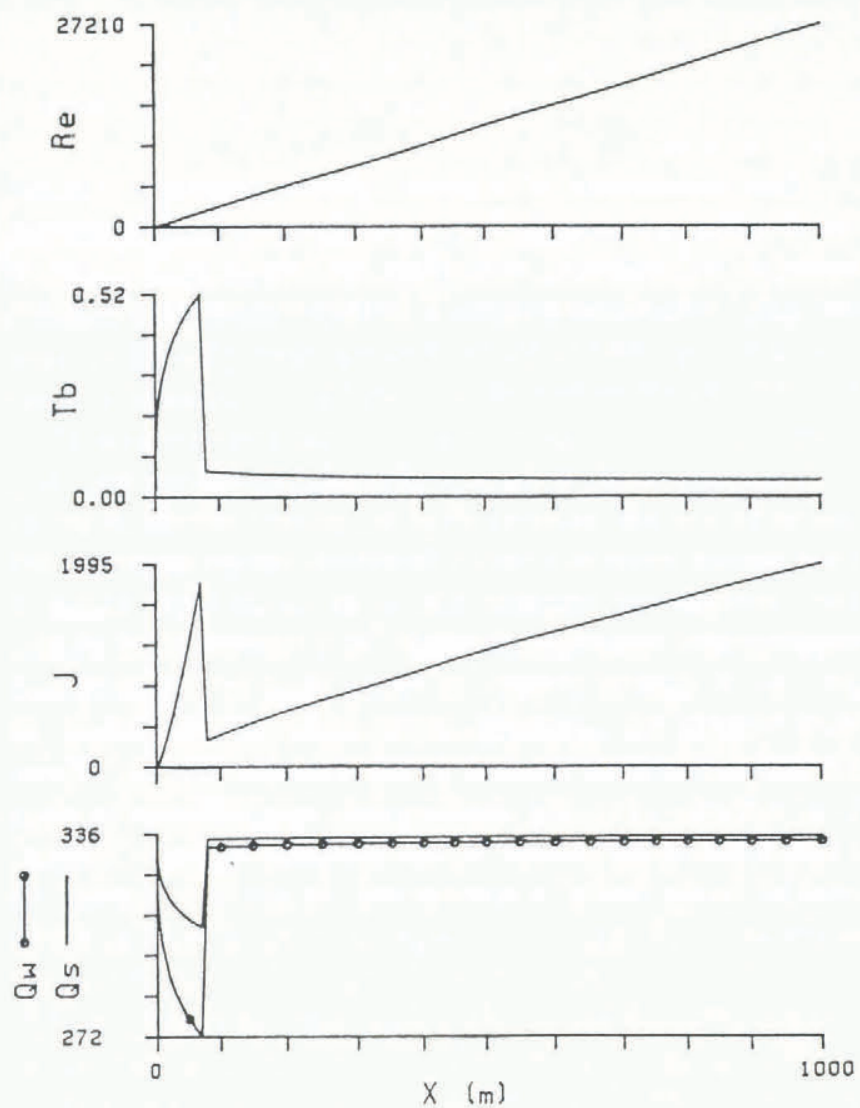

Fig. 6. As for Figure 2, but with $T_{a}=4^{\circ} \mathrm{C}$, $u_{a}=4 \mathrm{~ms}^{-1}, \theta=5^{\circ}$ and $R=40 \mathrm{~mm} \mathrm{~h}^{-1}$.
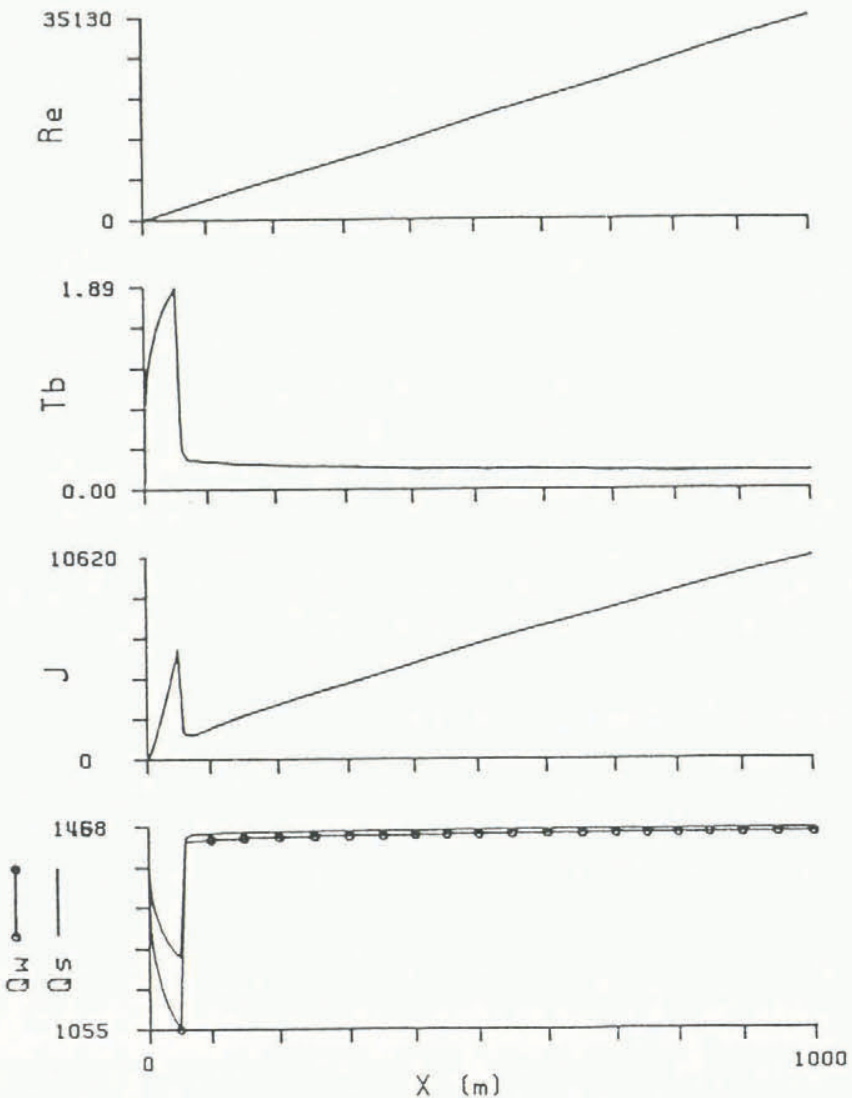

Fig. 7. As for Figure 2, but with $T_{a}=10^{\circ} \mathrm{C}$, $u_{a}=10 \mathrm{~ms}^{-1}, \theta=5^{\circ}$ and $R=40 \mathrm{~mm} \mathrm{~h}^{-1}$. 
configuration (i.e. the boundary condition) would require a period of days to occur, and the assumption of constant boundary conditions would apply for shorter time intervals.

The assumption of a planar glacier surface is unrealistic. Glaciers usually have complex surfaces involving bumps and hollows, and often the uppermost layer of ice has a somewhat porous structure, sometimes called a "weathering crust". Water flowing through such a crust has greater effective contact with the ice, promoting heat transfer to the ice as compared to the assumed situation.

Supraglacial flow is in reality three-dimensional and tends to concentrate into discrete turbulent rills or channels within relatively short distances rather than exhibit two-dimensional laminar flow as assumed here. Maps of supraglacial drainage patterns, as presented, for example, by Knighton (1985), indicate that non-channelized flow lengths are normally of the order of $100-200 \mathrm{~m}$. In addition, raindrop impact would enhance mixing. Thus, heat transfer in reality should occur more efficiently than computed in the model in the laminar region. Consequently, lower water temperatures would be required to maintain heat transfer through the run-off layer and the impact of heat advection on the spatial variation of melt rates would be less in reality than indicated in the model.

Taking the simulation results as being upper limits on the magnitude of the impact of sensible-heat advection on melt patterns, it can be argued that such advection cannot produce macro-scale variations in melt and surface morphology as has been argued by Kazanskiy (1982), except perhaps under conditions of heavy rainfall and/or rapid melt. However, advection may have microscale effects, especially in a region where turbulent rills or channels are fed by laminar inflow: the release of advected sensible heat at the point where the inflow meets the turbulent flow would augment frictional melt and promote channelization.

\section{CONCLUSIONS}

Advection of sensible heat by a supraglacial run-off layer during rainfall and the consequences for spatial variations of melt have been investigated through numerical simulation. The simulations indicate that advection cannot influence macro-scale melt patterns and surface morphology except perhaps under heavy rainfall and/or rapid melt conditions, but can possibly cause micro-scale variations in ice melt. One-dimensional energy-balance models, which have normally been applied over glacier surfaces, should remain valid for most conditions.

\section{ACKNOWLEDGEMENTS}

G. K. C. Clarke made suggestions regarding the approach to the problem and W. G. Bailey and M. G. Marcus reviewed earlier versions of the manuscript.

\section{REFERENCES}

Anderson, E. A. 1973. National Weather Service river forecast system - snow accumulation and ablation model. NOAA Tech. Memo. NWS 17.

Clarke, G. K. C. 1982. Glacier outburst floods from "Hazard Lake", Yukon Territory, and the problem of flood magnitude prediction. J. Glaciol., 28(98), 3-21.

Colburn, A.P. 1933. Note on the calculation of condensation where a portion of the condensate layer is in turbulent flow. Trans. Am. Inst. Chem. Eng., 30, 187-193.

Hay, J.E. and B. B. Fitzharris. 1988. A comparison of the energy-balance and bulk-aerodynamic approaches for estimating glacier melt. J. Glaciol., 34(117), 145153.

Henderson, F. M. 1966. Open channel flow. New York, MacMillan.

Kazanskiy, A. B. 1982. The importance of the structure of the glacier internal and external runoff system of channels and streams to glacier activity. International Association of Hydrological Sciences Publication 138 (Symposium at Exeter 1982 - Hydrological Aspects of Alpine and High-Mountain Areas), 123-130.

Knighton, A.D. 1985. Channel form adjustment in supraglacial streams, Austre Okstindbreen, Norway. Arct. Alp. Res., 17(4), 451-466.

Kreith, F. 1973. Principles of heat transfer. Third edition. New York, Intext Educational Publishers.

McAdams, W. H. 1954. Heat transmission. Third edition. New York, McGraw-Hill.

Marcus, M. G., R. D. Moore and I. F. Owens. 1985. Shortterm estimates of surface energy transfers and ablation on the lower Franz Josef Glacier, South Westland, New Zealand. N.Z. J. Geol. Geophys., 28(3), 559567.

Martin, S. 1975. Wind regimes and heat exchange on Glacier de Saint-Sorlin. J. Glaciol., 14(70), 91-105.

Munro, D.S. 1989. Surface roughness and bulk heat transfer on a glacier: comparison with eddy correlation. J. Glaciol., 35(121), 343-348.

Nakawo, M. and G. J. Young. 1982. Estimate of glacier ablation under a debris layer from surface temperature and meteorological variables. J. Glaciol., 28(98), 29-34.

Nusselt, W. 1916. Die Oberflächenkondensation des Wasserdampfes. Zeitschrift des Vereins Deutscher Ingenieure, 60, 541-569.

Spring, U. and K. Hutter. 1981. Numerical studies of jökulhlaups. Cold Reg. Sci. Technol., 4(3), 227-244.

The accuracy of the references in the text and in this list is the responsibility of the author, to whom queries should be addressed. 